\title{
Three years of global carbon monoxide from SCIAMACHY: comparison with MOPITT and first results related to the detection of enhanced $\mathrm{CO}$ over cities
}

\author{
M. Buchwitz, I. Khlystova, H. Bovensmann, and J. P. Burrows \\ Institute of Environmental Physics (IUP), University of Bremen FB1, Bremen, Germany \\ Received: 7 December 2006 - Published in Atmos. Chem. Phys. Discuss.: 11 January 2007 \\ Revised: 26 March 2007 - Accepted: 30 April 2007 - Published: 11 May 2007
}

\begin{abstract}
Carbon monoxide (CO) is an important atmospheric constituent affecting air quality and climate. SCIAMACHY on ENVISAT is currently the only satellite instrument that can measure the vertical column of $\mathrm{CO}$ with nearly equal sensitivity at all altitudes down to the Earth's surface because of its near-infrared nadir observations of reflected solar radiation. Here we present three years' (2003-2005) of SCIAMACHY CO columns consistently retrieved with the latest version of our retrieval algorithm (WFMDv0.6). We describe the retrieval method and discuss the multi-year global CO data set focusing on a comparison with the operational CO column data product of MOPITT. We found reasonable to good agreement ( $\sim 20 \%)$ with MOPITT, with the best agreement for 2004. We present detailed results for various regions (Europe, Middle East, India, China) and discuss to what extent enhanced levels of $\mathrm{CO}$ can be detected over populated areas including individual cities. The expected $\mathrm{CO}$ signal from cities is close to or even below the detection limit of individual measurements. We show that cities can be identified when averaging long time series.
\end{abstract}

\section{Introduction}

Air pollution resulting from fossil fuel combustion has become an important problem, especially for countries with an increasing energy demand and inherent fuel consumption such as China. Carbon monoxide (CO) contributes to air pollution because it is toxic in large concentrations, acts as a pre-curser to tropospheric ozone and - because $\mathrm{CO}$ is the leading sink of the hydroxyl radical $(\mathrm{OH})$ - largely determines the self-cleansing efficiency of the troposphere (see, e.g., Bergamaschi et al., 2000, and references given therein). $\mathrm{CO}$ is highly variable in space and time and accurate mea-

Correspondence to: M. Buchwitz

(michael.buchwitz@iup.physik.uni-bremen.de) surements of its spatial pattern and time evolution is required for example for air quality monitoring and forecasting applications.

SCIAMACHY (Bovensmann et al., 1999), because of its near-infrared nadir observations, is the first and currently only satellite instrument that can measure $\mathrm{CO}$ columns with nearly equal sensitivity at all altitude levels including the boundary layer. This is demonstrated by SCIAMACHY's CO column averaging kernels (Buchwitz et al., 2004) which are close to unity throughout the troposphere. The physical reason why SCIAMACHY has nearly equal sensitivity at all altitudes is that SCIAMACHY observes solar radiation which has been reflected at the Earth's surface combined with the fact that the spectral region used for $\mathrm{CO}$ column retrieval is relatively transparent. The reflected solar radiation measured by SCIAMACHY has therefore passed the entire atmosphere down to the Earth's surface.

Accurate CO column retrieval from SCIAMACHY is however not trivial, because the $\mathrm{CO}$ lines are weak and superimposed by much stronger absorption lines of water vapor and methane, because of an ice layer that grows on the detector, and because of an increasing number of bad or dead detector pixels (Gloudemans et al., 2005). Several groups have developed retrieval algorithms for CO from SCIAMACHY and the results have been published in recent papers (Buchwitz et al., 2004, 2005, 2006; Frankenberg et al., 2005; de Laat et al., 2006; Gloudemans et al., 2006). Here we present for the first time three years (2003-2005) of consistently retrieved SCIAMACHY CO columns and discuss the ability of SCIAMACHY to detect enhanced levels of CO corresponding to highly populated areas including individual cities. To assess the quality of our data product we present a comparison with MOPITT using the operational CO vertical column data product of MOPITT. The SCIAMACHY CO columns discussed here were retrieved using the scientific retrieval algorithm WFM-DOAS version 0.6 (WFMDv0.6). 
WFMDv0.6 is similar to (but not identical with) WFMDv0.5 which has been used to retrieve $\mathrm{CO}$ for the year 2003 (Buchwitz et al., 2006). The WFMDv0.5 year 2003 data set has been validated by comparison with a global network of ground-based Fourier Transform Infra Red (FTIR) stations (Dils et al., 2006a) and it was found that agreement is typically within $10-20 \%$. Recently a first comparison of the WFMDv0.6 CO has been performed (Dils et al., 2006b) using seven European FTIR stations for the years 2003 and 2004. In that study it has been found that the average difference between SCIAMACHY and FTIR CO is about $10 \%$ for 2003 and about $1 \%$ for 2004 . The positive bias of SCIAMACHY CO for 2003 and the much lower bias for 2004 is consistent with the results presented here based on a comparison with MOPITT. The standard deviation of the difference between SCIAMACHY and FTIR CO is about $20 \%$ for both years. This roughly corresponds to the SCIAMACHY CO retrieval precision for the spectral fitting window used for WFMDv0.6 CO retrievals (the instrument noise related error is about $10 \%$ if the entire CO band is used; for WFMDv0.6 however not all lines covered by SCIAMACHY are used). The correlation coefficient of the SCIAMACHY and the FTIR CO is about 0.8 also indicating good agreement of the SCIAMACHY WFMDv0.6 CO columns with the FTIR measurements.

In order to generate a consistent multi-year data set the WFMDv0.5 algorithm had to be adjusted mainly in order to take into account the increasing number of bad and dead detector pixels but also to consider updates of spectroscopic line parameters and the availability of new SCIAMACHY spectra with improved calibration (details are given in Sect. 3).

The paper is organized as follows: after a short overview about the SCIAMACHY instrument and the retrieval method the $\mathrm{CO}$ measurements are presented and discussed in detail. The discussion focuses on a quantitative comparison with MOPITT and on regional results.

\section{The SCIAMACHY instrument}

SCIAMACHY (Bovensmann et al., 1999) is a spectrometer aboard the European environmental satellite ENVISAT which measures reflected, scattered and transmitted solar radiation in the spectral region 214-2380 nm at moderate spectral resolution $(0.2-1.6 \mathrm{~nm})$. On the Earth's day side SCIAMACHY mainly performs a sequence of alternating nadir and limb observations (each lasting about one minute). For this paper only the nadir measurements (and the solar observations) are relevant and only channel 8 which covers the spectral region $2265-2380 \mathrm{~nm}$ with a spectral resolution of about $0.24 \mathrm{~nm}$. The horizontal resolution of the nadir measurements depends on orbital position and spectral interval but for CO is typically $120 \mathrm{~km}$ across track times $30 \mathrm{~km}$ along track. SCIAMACHY performs very well with two major exceptions which are relevant for $\mathrm{CO}$ retrieval, namely the channel 8 ice layer issue and the increasing number of bad and dead detector pixels (Gloudemans et al., 2005) (more details are given below).

\section{Retrieval algorithm WFM-DOAS}

The Weighting Function Modified Differential Optical Absorption Spectroscopy (WFM-DOAS) retrieval algorithm has already been described in detail elsewhere (Buchwitz et al., 2000 b, 2004, 2006). Here we give a short overview of WFMDOAS including a discussion of the main differences between the previous version 0.5 (Buchwitz et al., 2006) and version 0.6 which has been used to generate the data set discussed in this paper.

WFM-DOAS is a least squares method based on scaling pre-selected vertical profiles (a single CO profile is used for WFMDv0.6). The fit parameters for the trace gases are directly the vertical columns. The logarithm of a linearized radiative transfer model plus a low-order polynomial is fitted to the logarithm of the ratio of a measured nadir radiance and solar irradiance spectrum, i.e., observed sun-normalized radiance. The least-squares WFM-DOAS equation can be written as follows (the fit parameters are underlined):

$$
\left\|\ln I_{i}^{\mathrm{obs}}-\ln I_{i}^{\bmod }(\underline{\hat{\mathbf{V}}})\right\|^{2} \equiv\left\|\operatorname{RES}_{i}\right\|^{2} \rightarrow \min .,
$$

where the linearized radiative transfer model is given by

$$
\begin{aligned}
\ln I_{i}^{\bmod }(\underline{\hat{\mathbf{V}}}) & =\ln I_{i}^{\bmod }(\overline{\mathbf{V}}) \\
+ & \left.\left.\sum_{j=1}^{J} \frac{\partial \ln I_{i}^{\bmod }}{\partial V_{j}}\right|_{\bar{V}_{j}} \underline{\left(\hat{V}_{j}\right.}-\bar{V}_{j}\right)+P_{i} \underline{\left(\underline{a_{m}}\right)} .
\end{aligned}
$$

Index $i$ refers to the center wavelength $\lambda_{i}$ of detector pixel number $i$. The components of vectors $\mathbf{V}$, denoted $V_{j}$, are the vertical columns of all trace gases which have absorption lines in the selected spectral fitting window (here: $\mathrm{CO}$, $\mathrm{CH}_{4}$, and $\mathrm{H}_{2} \mathrm{O}$ ). The fit parameters are the desired trace gas vertical columns $\hat{V}_{j}$ and the polynomial coefficients $a_{m}$. An additional fit parameter also used (but omitted in Eqs. (1) and (2)) is the shift (in Kelvin) of a pre-selected temperature profile. This fit parameter has been added in order to take the temperature dependence of the trace gas absorption cross-sections into account. The fit parameter values are determined by minimizing (in least-squares sense) the difference between observation ( $\ln I_{i}^{\text {obs }}$ ) and WFM-DOAS model $\left(\ln I_{i}^{\mathrm{mod}}\right.$ ), i.e., fit residuum $\mathrm{RES}_{i}$, for all spectral points $\lambda_{i}$ simultaneously. A derivative, or weighting function, with respect to a vertical column refers to the change of the top-ofatmosphere radiance caused by a change (here: scaling) of a pre-selected trace gas vertical profile. Because water vapor is highly variable and the water vapor absorption lines 

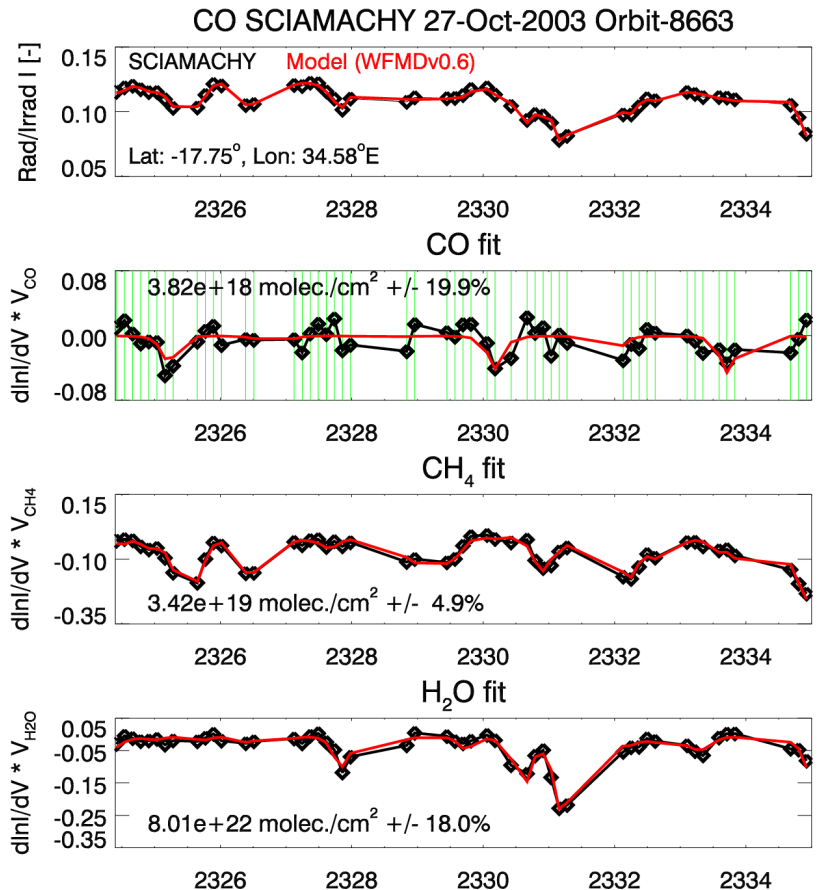

Fit Residuum (relative difference measurement - model)

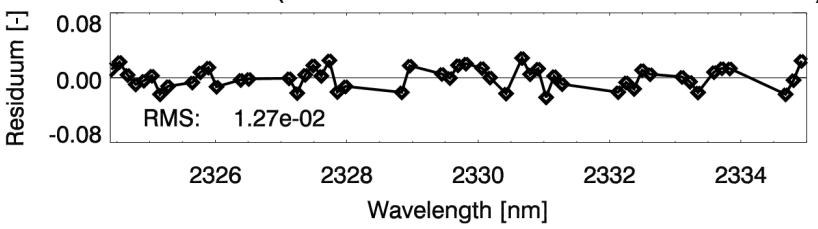

Fig. 1. Example of a WFM-DOAS CO fit for a scene with significantly elevated $\mathrm{CO}$ due to biomass burning over Mozambique, Africa, measured on 27 October 2003 (orbit 8663). The top panel shows the measured sun-normalized radiance (black symbols) and the fitted WFM-DOAS linearized radiative transfer model (red line). The bottom panel shows the (total) fit residuum, i.e., the relative difference between the measurement and the WFM-DOAS model after the fit. The root mean square (RMS) relative difference between the measurement and the model is 0.0127 , corresponding to a difference of $1.27 \%$. The second panel shows details of the CO fit. The red line is the scaled $\mathrm{CO}$ weighting function, i.e., the scaled derivative of the sun-normalized radiance with respect to a change of the CO column (see Eqs. 1 and 2). The scaling factor is the retrieved $\mathrm{CO}$ column. The symbols denote the $\mathrm{CO}$ fit residuum which is defined as the scaled $\mathrm{CO}$ weighting function (red curve) plus the total fit residuum (shown in the bottom panel). The retrieved CO column is $3.82 \cdot 10^{18}$ molecules $/ \mathrm{cm}^{2} \pm 20 \%$. The green vertical lines indicate the spectral position of the detector pixels not classified bad or dead by the Bad and Dead detector Pixel Mask (BDPM) used for WFMDv0.6. The following two panels are similar as the second panel, but show details of the methane and water vapor spectral fit.

are relatively strong, WFM-DOAS has been implemented as an iterative scheme with respect to the water vapor vertical column fit. The WFM-DOAS reference spectra are the logarithm of the sun-normalized radiance and its derivatives. They are computed with a radiative transfer model (Buch-

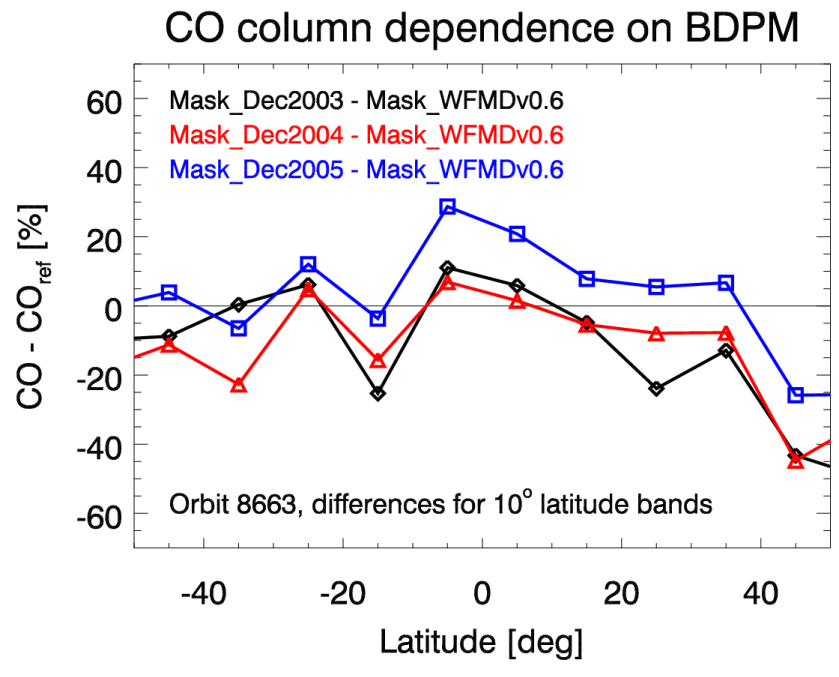

Fig. 2. Dependence of the retrieved CO column on the choice of the Bad and Dead detector Pixel Mask (BDPM). CO columns have been retrieved from orbit 8663 from 27 October 2003 using four different BDPMs, namely the pixel mask used for WFMDv0.6 and three other pixel masks generated by SRON (see main text), valid for December 2003, December 2004, and December 2005. Shown is the difference between the average $\mathrm{CO}$ in 10 degrees latitude bands relative to the $\mathrm{CO}$ column retrieved using the WFMDv0.6 pixel mask. As can be seen, the choice of the BDPM has a significant impact on the retrieved $\mathrm{CO}$ column.

witz et al., 2000a) for assumed (e.g., climatological) "mean" columns $\overline{\mathbf{V}}$. Multiple scattering is fully taken into account. The least-squares problem (Eqs. 1 and 2) can also be expressed in the following vector/matrix notation: Minimize $\|\mathbf{y}-\mathbf{A} \mathbf{x}\|^{2}$ with respect to $\mathbf{x}$. The solution is $\hat{\mathbf{x}}=\mathbf{C}_{\mathbf{x}} \mathbf{A}^{T} \mathbf{y}$ where $\mathbf{C}_{\mathbf{x}} \equiv\left(\mathbf{A}^{T} \mathbf{A}\right)^{-1}$ is the covariance matrix of solution $\hat{\mathbf{x}}$. The errors of the retrieved columns, $\sigma_{\hat{V}_{j}}$, are estimated as follows: $\quad \sigma_{\hat{V}_{j}}=\sqrt{\left(\mathbf{C}_{\mathbf{x}}\right)_{j j} \times \sum_{i} \operatorname{RES}_{i}^{2} /(m-n)}$, where $\left(\mathbf{C}_{\mathbf{x}}\right)_{j j}$ is the $j$-th diagonal element of the covariance matrix, $m$ is the number of spectral points in the fitting window and $n$ is the number of linear fit parameters $\left(\mathrm{RES}_{i}\right.$ is the spectral fit residuum, see Eqs. 1 and 2). Figure 1 illustrates all this by showing a WFM-DOAS example fit.

Version 0.6 differs from version 0.5 in several aspects: (i) use of a slightly smaller spectral fitting window (2324.4$2335.0 \mathrm{~nm}$ ) covering four CO lines; see Fig. 1 which shows a WFMDv0.6 example fit, (ii) an optimized so called bad and dead detector pixel mask that defines the to be excluded detector pixels for the time period 2003-2005 (details are given below), (iii) use of better calibrated spectra (Level 1 version 5 instead of version 4) with nominal calibration (for WFMDv0.5 we had to improve the dark signal correction but this is not needed any more for Level 1 version 5), (iv) use of Hitran 2004 (Rothman et al., 2005) line parameters instead of Hitran 2000/2001 (Rothman et al., 2003), (v) slight modification of the quality flag that defines a good measurement 


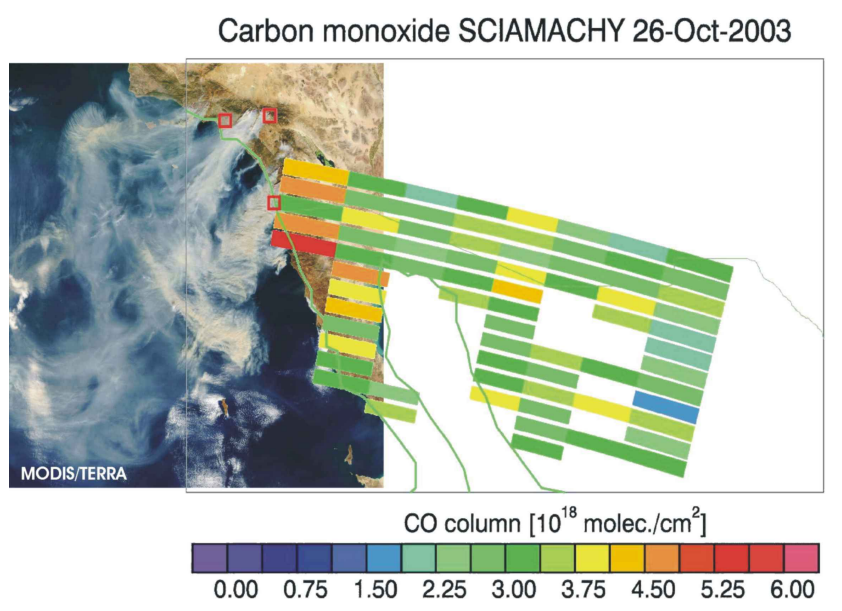

Fig. 3. Single overpass CO columns as measured by SCIAMACHY on 26 October 2003 over Southern California, USA. The flight direction of ENVISAT is from north(-east) to south(-west). Only the SCIAMACHY ground pixels which were (automatically) classified good by the WFMDv0.6 retrieval algorithm are shown. As can be seen, all of the measurements over water are classified bad for this scene (there are also some gaps over land mostly due to clouds which are identified using the simultaneously retrieved methane columns). Shown is a nearly rectangular block (one state) of nadir measurements which corresponds to about one minute of measurements (the gaps before (towards top right) and after (towards bottom left) are due to the limb observations). Each (nearly east to west) scan line consists of eight ground pixels each covering an area of about $30 \mathrm{~km}$ along track times $120 \mathrm{~km}$ across track. The CO measurements are plotted on top of a MODIS/Terra reflectivity map from measurements of the same day which shows extended smoke plumes originating from fires located for example near San Diego (indicated by the most southward located red square). As can be seen, the highest CO columns are measured near San Diego close to the fires. The MODIS image has been obtained from earthobservatory.nasa.gov.

(e.g., the root-mean-square (RMS) of the fit residuum has to be better than 0.02 for WFMDv0.6 compared to 0.025 for WFMDv0.5).

The main difference compared to WFMDv0.5 is the use of a different Bad and Dead detector Pixel Mask (BDPM). Note that for this study no distinction is made between a dead detector pixel (which shows no or very low response or has a very high dark signal) and a bad detector pixel (which shows reponse but has quite high dark signal). For this study a detector pixel is either classified useful or not useful, i.e., dead or bad. The BDPM is a binary mask which defines for each detector pixel if it is useful, i.e., if it will be considered for retrieval or not. For channel 8 (SCIAMACHY's only CO channel) it has been found that the number of bad and dead pixels increases on average nearly linearly with time (see web page of SRON: http://www.sron.nl). Processing year 2004 and 2005 spectra with the pixel mask which had been used for year 2003 WFMDv0.5 processing was not possible due

\section{CO columns SCIAMACHY (WFMDv0.6)}
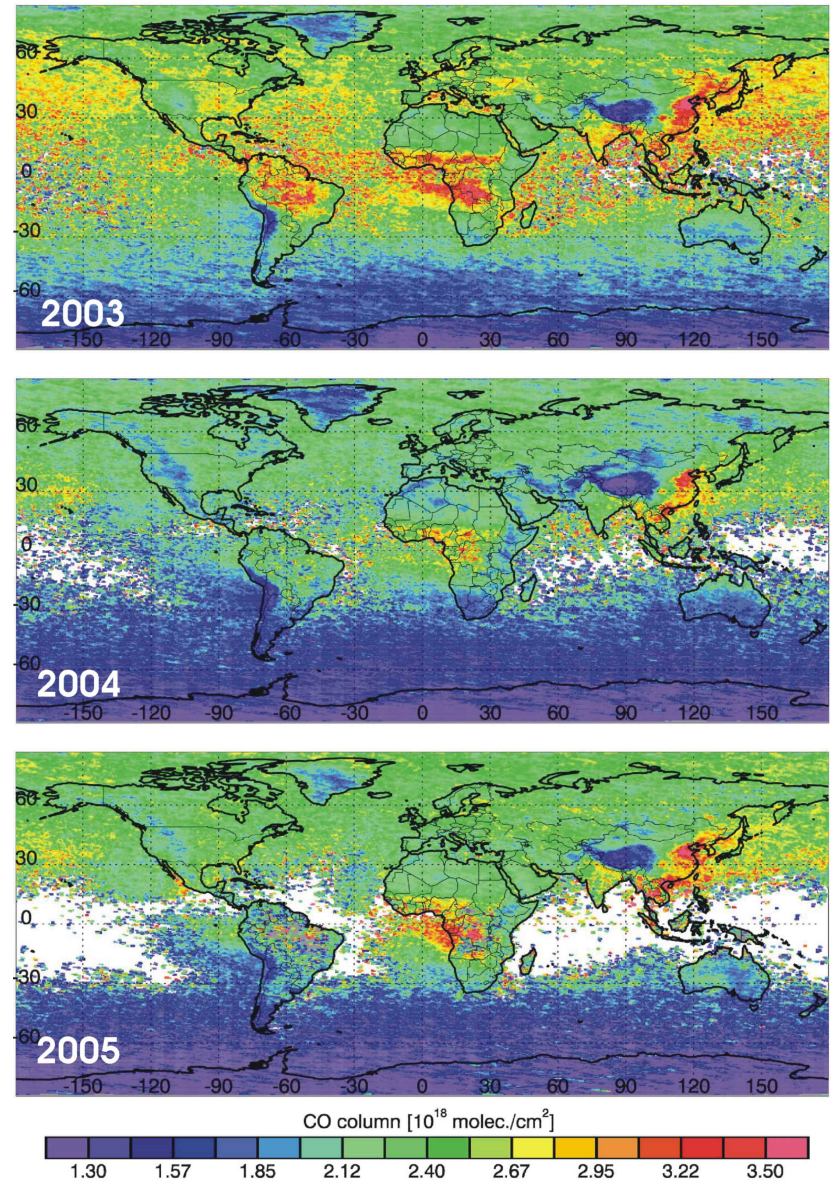

Fig. 4. Yearly averages of the SCIAMACHY WFMDv0.6 CO column data product. All data for which the WFMDv0.6 quality flag (which is part of the data product) indicates a successful measurement have been averaged.

to additional bad and dead pixels in 2004 and 2005. There are basically two options to deal with this (i) use of time dependent pixel masks (e.g., the ones generated at SRON available from http://www.sron.nl/ rienk/update_sronserver/ BDPMs/DataBase/SelectedMasks.php), or (ii) use of a static pixel mask optimized for the time period of interest (here: 2003-2005). We have investigated both options and decided to use the latter approach. We have found that the retrieved CO column depends significantly on which detector pixels are considered in the fit and which are not, i.e., on the pixel mask. This is illustrated in Fig. 2. This shows that a time dependence of the retrieved CO columns is introduced by using a time dependent pixel mask. In order to avoid (or at least to minimize) this we defined a static pixel mask by analyzing fit residuals of measurements covering the 20032005 time period. The WFMDv0.6 pixel mask which resulted from this exercise is identical (as much as possible) with the WFMDv0.5 pixel mask except that several pixels 

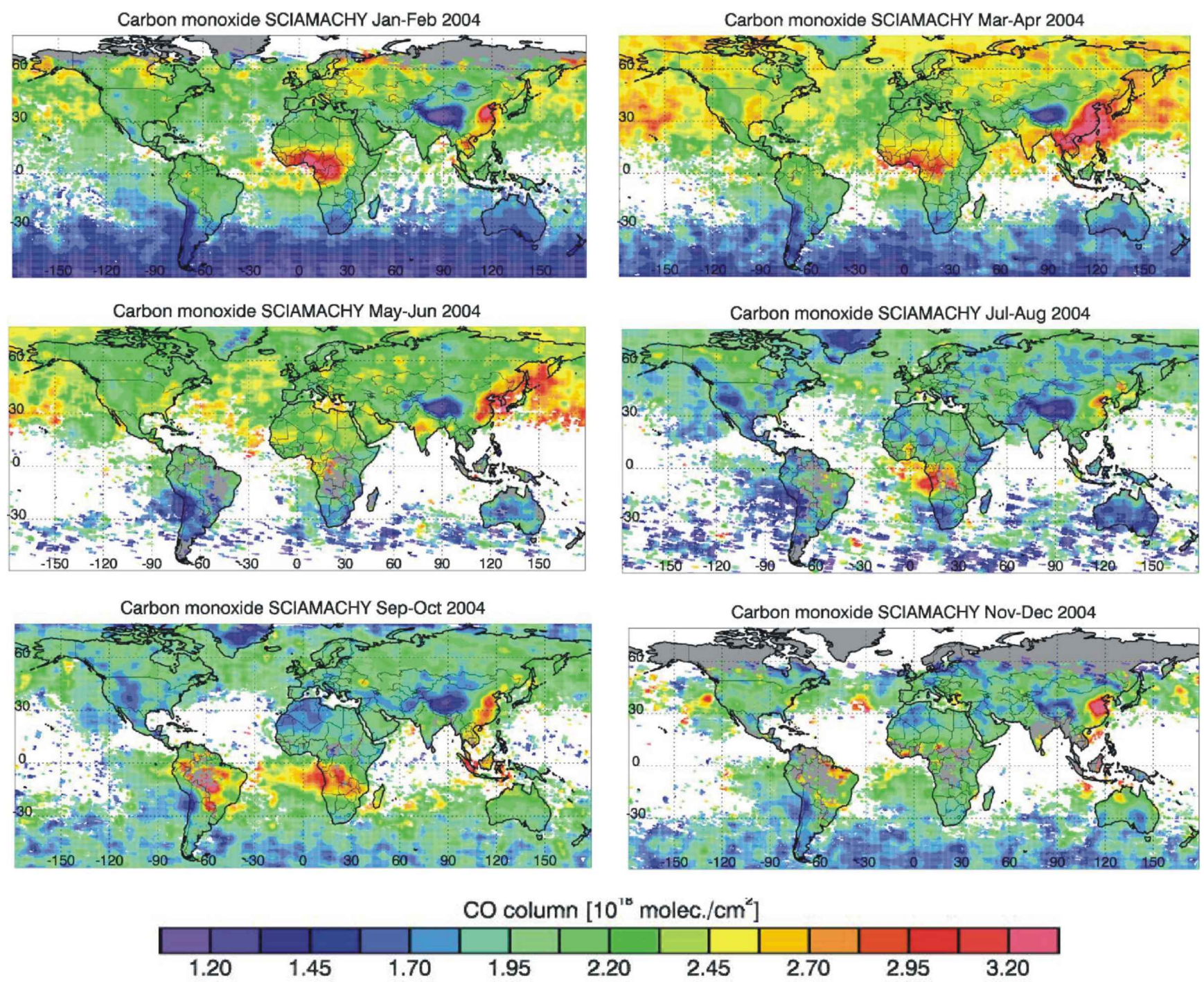

Fig. 5. Year 2004 bi-monthly averages of the SCIAMACHY WFMDv0.6 CO column data product. The individual measurements have been gridded and smoothed but data gaps have not been filled. All data have been averaged for which the WFMDv0.6 quality flag indicates a successful measurement.

had to be excluded because they resulted (at a certain point in time in the investigated time period) in large spikes in the fit residuum due to either very high noise or (nearly) no response to the incoming light level. It has to be pointed out however that even when using a single mask this does not guarantee that the data are entirely free of a time dependent bias (see discussion in Sect. 4).

\section{Discussion of the year 2003-2005 data set}

In the following we mainly present spatially and temporally averaged measurements with the exception of Fig. 3 which illustrates the spatial sampling. Figure 3 shows individual SCIAMACHY CO measurements obtained on 26 October 2003 over Southern California when large areas were burning near Los Angeles and San Diego. Despite the large footprint size and the imperfect match with the location of the fires Fig. 3 shows that the elevated $\mathrm{CO}$ resulting from the fires can be detected using single overpass data. Figure 3 also shows only those ground pixels for which the $\mathrm{CO}$ measurements are classified successful by the WFMDv0.6 quality flag. The fraction of ground pixels over water classified successful is in general significantly lower compared to the fraction of measurements over land (for this scene all ground pixels over water are rejected but as shown later this is not always the case). This is because of the low reflectivity of water in the near-infrared which results in low signal and low signal-tonoise ratios and therefore in worse spectral fits. The rootmean-square (RMS) of the fit residuum (difference between the measurement and the fitted radiative transfer model) is 
Carbon monoxide SCIAMACHY 14-31 July 2004

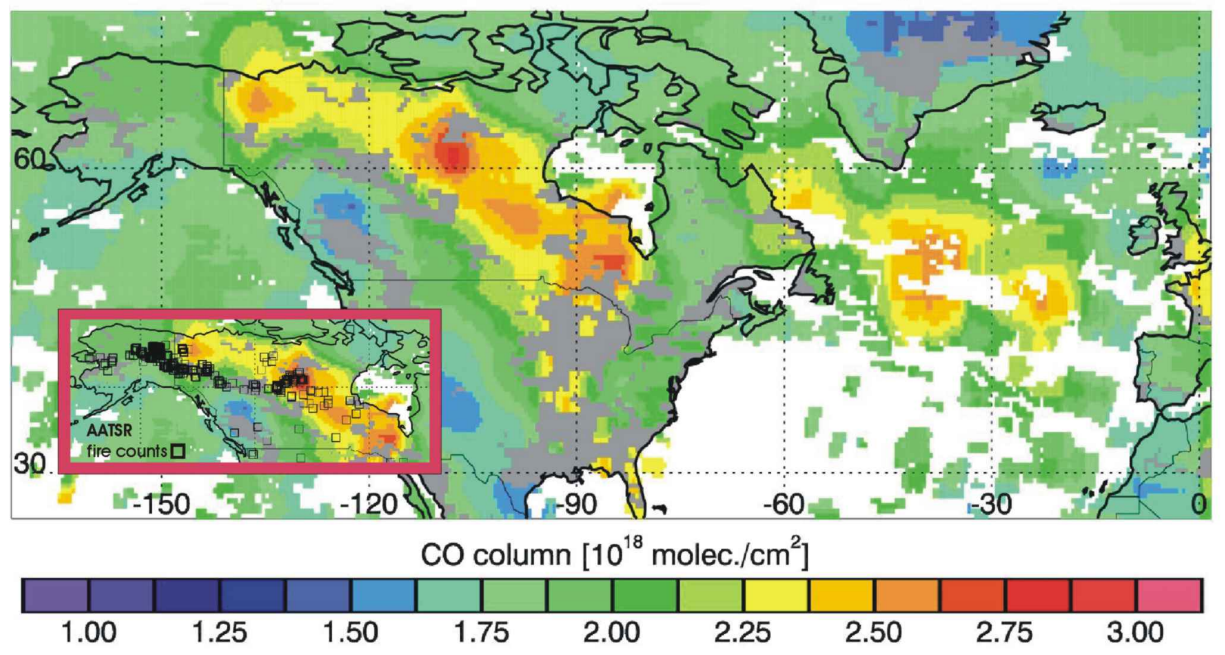

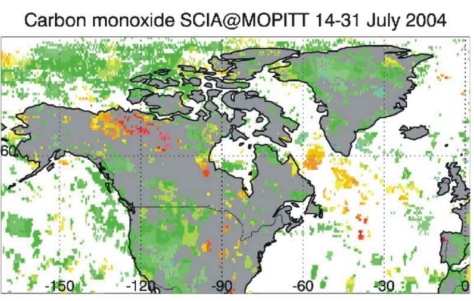

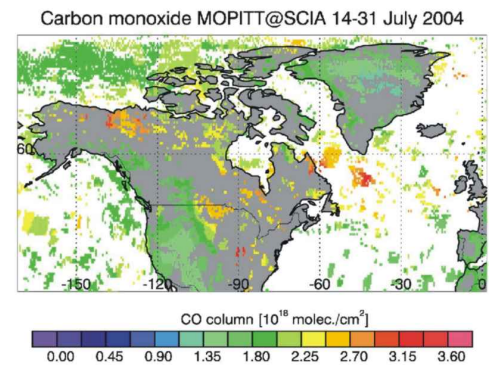

Fig. 6. Left: SCIAMACHY CO measurements over North America during the second half of July 2004 showing elevated levels of CO originating from fires in Alaska and Canada (the location of the fires is shown using AATSR fire counts obtained from http://dup.esrin.esa. it/ionia/wfa/index.asp displayed as black squares in the inlet figure (red marked rectangle)). The CO plume covers large parts of Canada and the Atlantic Ocean south of Greenland extending nearly to Europe. The two panels on the right hand side show the same scene but using only the SCIAMACHY measurements where MOPITT data are also available (top) and the MOPITT CO columns at locations where SCIAMACHY data are also available (bottom).

one of the criteria that determines if a measurement will be classified successful.

Figure 4 shows yearly averages of the three years of measurements discussed in this paper, namely 2003, 2004, and 2005. Well known major source regions of CO located in South America, central Africa, and China, are clearly visible for all three years with apparently considerable source strength variations from year to year. Also visible is the interhemispheric gradient with much higher $\mathrm{CO}$ columns over the northern hemisphere.

To display the seasonal variation of the CO columns Fig. 5 shows bi-monthly averages for the year 2004. The large scale pattern (seasonality of $\mathrm{CO}$ originating from biomass burning in Africa and South America; reduction of the interhemispheric gradient towards autumn, etc.) is consistent with what is known from previous measurements, e.g., from MOPITT (see, e.g., Bremer et al., 2004). In addition to these large scale features the maps also show considerable fine structure. For example the July/August average shows a narrow band of elevated $\mathrm{CO}$ extending from Alaska and Canada over the Atlantic ocean to close to Europe. Figure 6 shows that the high CO is due to fires in Alaska and Canada in July 2004. Figure 6 also shows that a similar pattern has also been observed with MOPITT and that the agreement between the SCIAMACHY and the MOPITT CO columns is very good, even over water.

A comparison with MOPITT for the entire time period for a region far from local sources (Sahara) is shown in Fig. 7.
For such a relatively clear and spatially homogeneous region a good agreement between both sensors can be expected as differences due to different overpass times, different spatial resolution and different altitude sensitivity only play a minor role under these circumstances. This is confirmed by Fig. 7 which shows that the CO columns as measured by both sensors agree very well with one exception: at the beginning of 2003 the SCIAMACHY CO is systematically higher by about $20 \%$.

Figures 9-11 show a comparison with MOPITT for six regions including strong source regions such as South America, South Africa, and South East Asia. The six regions are shown in Fig. 8. A similar comparison for the same six regions has been shown in Buchwitz et al. (2006) for the WFMDv0.5 CO year 2003 data set. The comparison of Fig. 6 of Buchwitz et al. (2006) with Fig. 9 shows that for January to October 2003 the WFMDv0.5 columns and the WFMDv0.6 columns are quite similar despite the differences between the two versions of the retrieval algorithm and the fact that many more orbits have been processed by WFMDv0.6 due to improved data availability. There are however also differences, for example over Europe in summer 2003. Here the old version 0.5 data set showed very high CO columns and also an exceptionally large scatter, not observed by the ground based FTIR measurements (Dils et al., 2006a). The CO version 0.6 data set presented here does not show this exceptional behaviour any more, most likely due to the improved calibration of the spectra. When comparing 


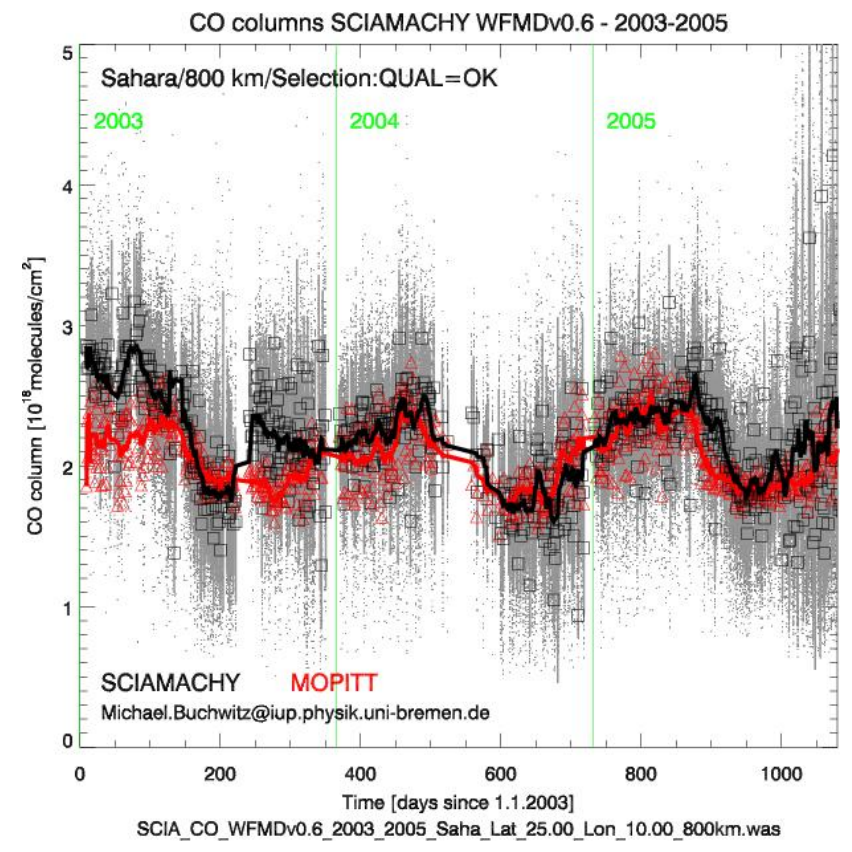

Fig. 7. Comparison of SCIAMACHY and MOPITT CO columns as measured over the Sahara $(800 \mathrm{~km}$ radius around $25 \mathrm{deg}$ latitude and 10 deg longitude) during 2003-2005. The grey dots are the individual SCIAMACHY measurements. The grey vertical lines show the standard deviation of the daily data and the grey squares their mean value. The thick black line has been obtained from the daily data by averaging using a 30 days running mean. The red triangles correspond to the daily mean MOPITT CO columns. The thick red line corresponds to their average (30 days running mean).

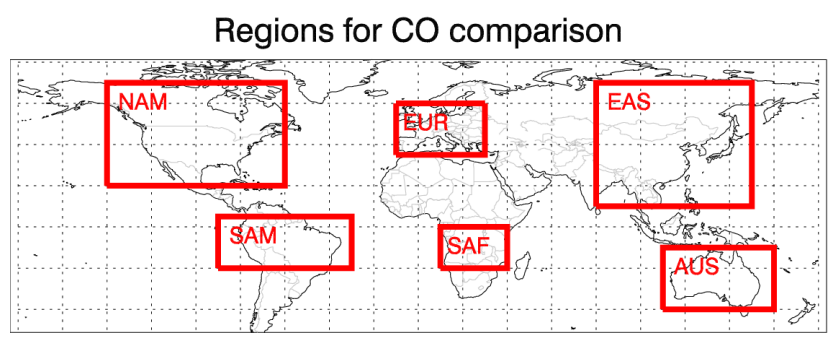

Fig. 8. Six regions defined for a detailed comparison of the SCIAMACHY WFMDv0.6 CO columns with MOPITT shown in Figs. 911.

Fig. 6 of Buchwitz et al. (2006) with Fig. 9 shown in this paper one may wonder why the MOPITT columns are different? The reason for this is that due to the different quality of the SCIAMACHY spectra, the SCIAMACHY measurements classified good are different for version 0.5 and version 0.6. As only those MOPITT data are selected where also a (good) SCIAMACHY measurement exists, also the daily averaged MOPITT columns change if the SCIAMACHY data selection changes.
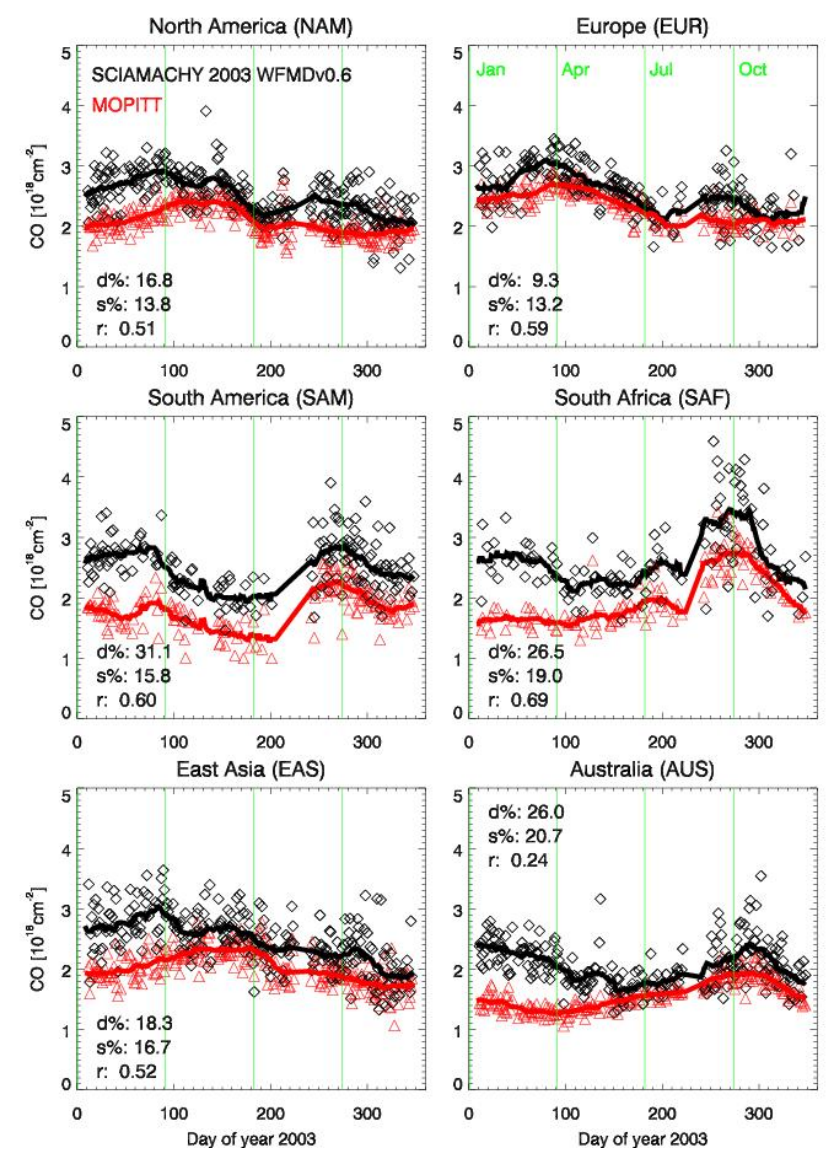

Fig. 9. Regional comparison of SCIAMACHY WFMDv0.6 CO columns (black) with MOPITT (red) for the year 2003. The location of the six regions is shown in Fig. 8. The symbols show the daily averages of all coincident grid points. For SCIAMACHY all measurements have been averaged for which the WFMDv0.6 quality flag indicates a successful measurement. The solid lines represent 30 days running averages. For each region the following quantities are shown which have been computed based on the (not smoothed) daily averages: $d \%$ is the mean difference SCIA-MOPITT in percent, $s \%$ denotes the standard deviation of the difference in percent, and $r$ is the correlation coefficient. The comparison method used here is exactly identical with the method used for WFMDv0.5 year 2003 data (Buchwitz et al., 2006) to enable a comparison of the two versions.

Figures 9-11 show that the best agreement with MOPITT is for the year 2004 (Fig. 10). The mean difference between the regional daily averages is typically less than $10 \%$, the standard deviation of the difference is typically less than $20 \%$ and the linear correlation coefficient is between 0.52 and 0.66. For 2003 and 2005 the agreement is not that good with SCIAMACHY CO being typically somewhat higher compared to MOPITT. Perfect agreement between both sensors cannot be expected because of different overpass times, different footprint size, and because of different altitude sensitivity. Especially the different altitude 

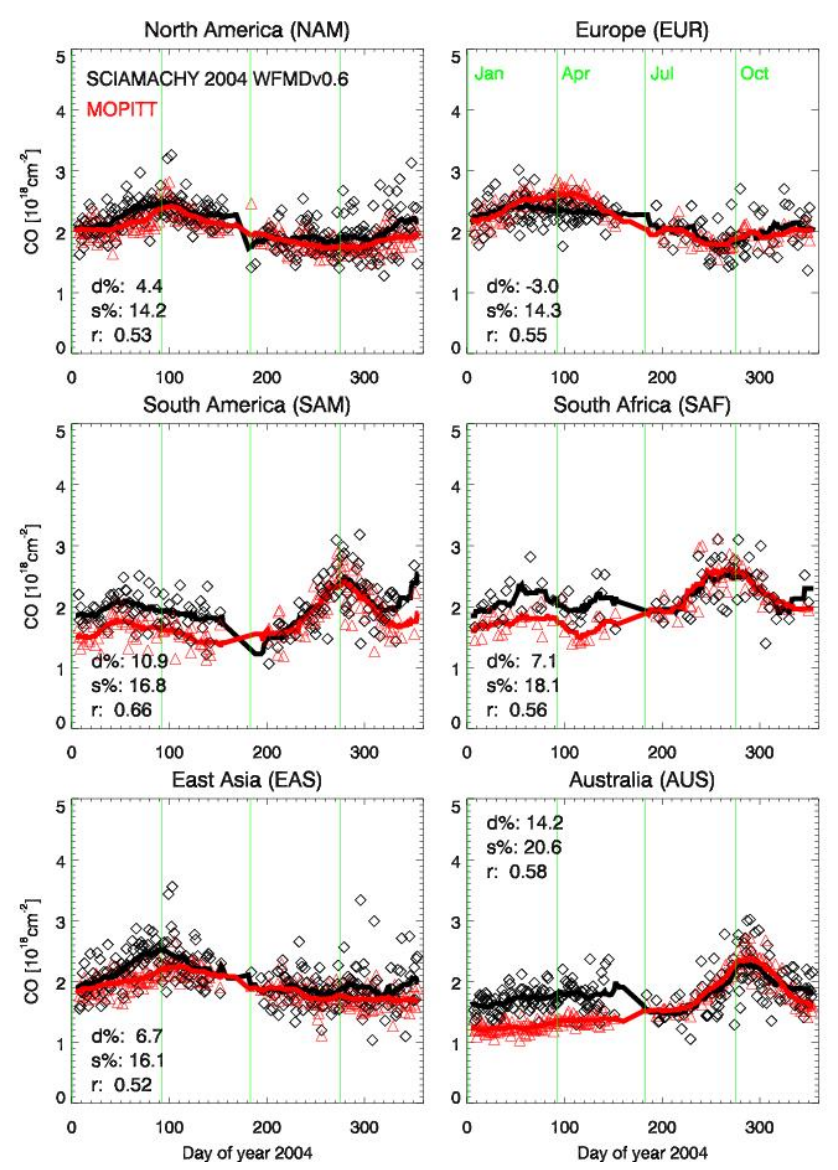

Fig. 10. As Fig. 9 but for the year 2004 .

sensitivity does strictly speaking not allow a direct comparison, as SCIAMACHY is also sensitive to the boundary layer whereas the sensitivity of MOPITT is close to zero in the boundary layer. Unfortunately, the SCIAMACHY measurements do not allow to retrieve height resolved CO information. Therefore it is not possible to apply the MOPITT averaging kernels to the SCIAMACHY retrievals to consider the different altitude sensitivities of the two sensors. At present we cannot exclude that at least partially the differences between SCIAMACHY and MOPITT are due to problems of the SCIAMACHY instrument. 2003 was the year with the largest changes of the channel 8 ice layer. The ice layer reduces the optical throughput of channel 8 (which reduces the signal to noise performance and therefore increases the random error of the CO columns) but also results in changes of the instrument slit function (which results in systematic errors of the retrieved CO columns). Our first order correction for the systematic errors caused by the ice layer is to normalize the retrieved $\mathrm{CO}$ columns with methane retrieved from the same fitting window (Buchwitz et al., 2006). Nevertheless, some error remains. 2005 is the year with the largest number of bad and dead detector pixels. Both effects may result in 2004 being on average the best of the three years.
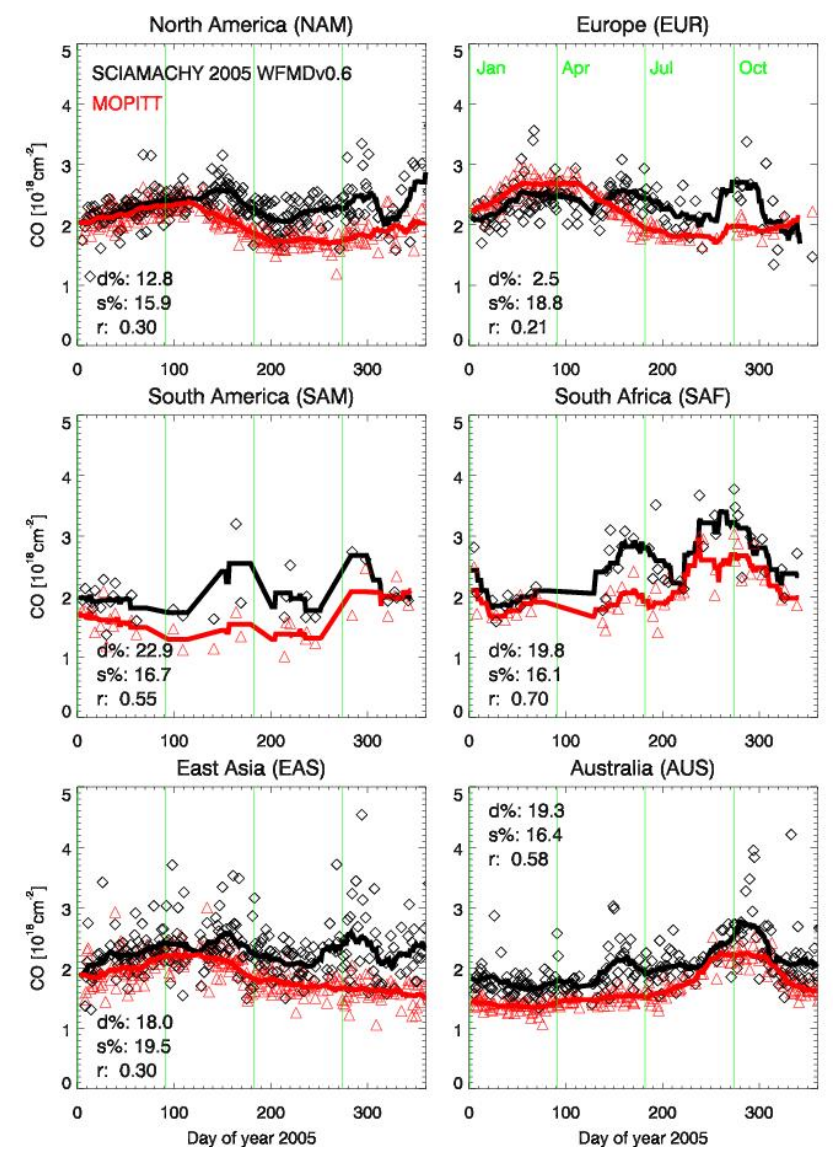

Fig. 11. As Fig. 9 but for the year 2005 .

The year 2005 comparison shown in Fig. 11 reveals that especially for South America and South Africa the number of data points is significantly reduced in comparison with 2003 and 2004 (see also Fig. 4). This is because in 2005 the percentage of the measurements being classified "bad" (see discussion of the WFM-DOAS quality flag in Sect. 3) is larger than for the two other years. To analyze this we looked at time series of CO columns over the Sahara located outside major source region with relatively high surface albedo and low cloud cover (using the same area also used for Fig. 7). We found that especially during the last third of 2005 the scatter of the RMS of the fit residuum increases from a typical range of $0.01-0.015$ to $0.01-0.03$ (see also Fig. 7). As "quality good" is only assigned to a measurement if the RMS is below 0.02 this means that many more measurements are rejected in 2005 compared to 2003 and 2004. To investigate this we have analyzed individual fits at various points in time in order to find out if one or more individual detector pixels are causing the observed increase of the RMS but we did not find a significant degradation of any of the individual detector pixels classified "good" in our WFMDv0.6 pixel mask, i.e. the one used for WFMDv0.6 retrieval. From this we conclude that the noise level of the entire spectrum in- 


\section{SCIAMACHY 2004}
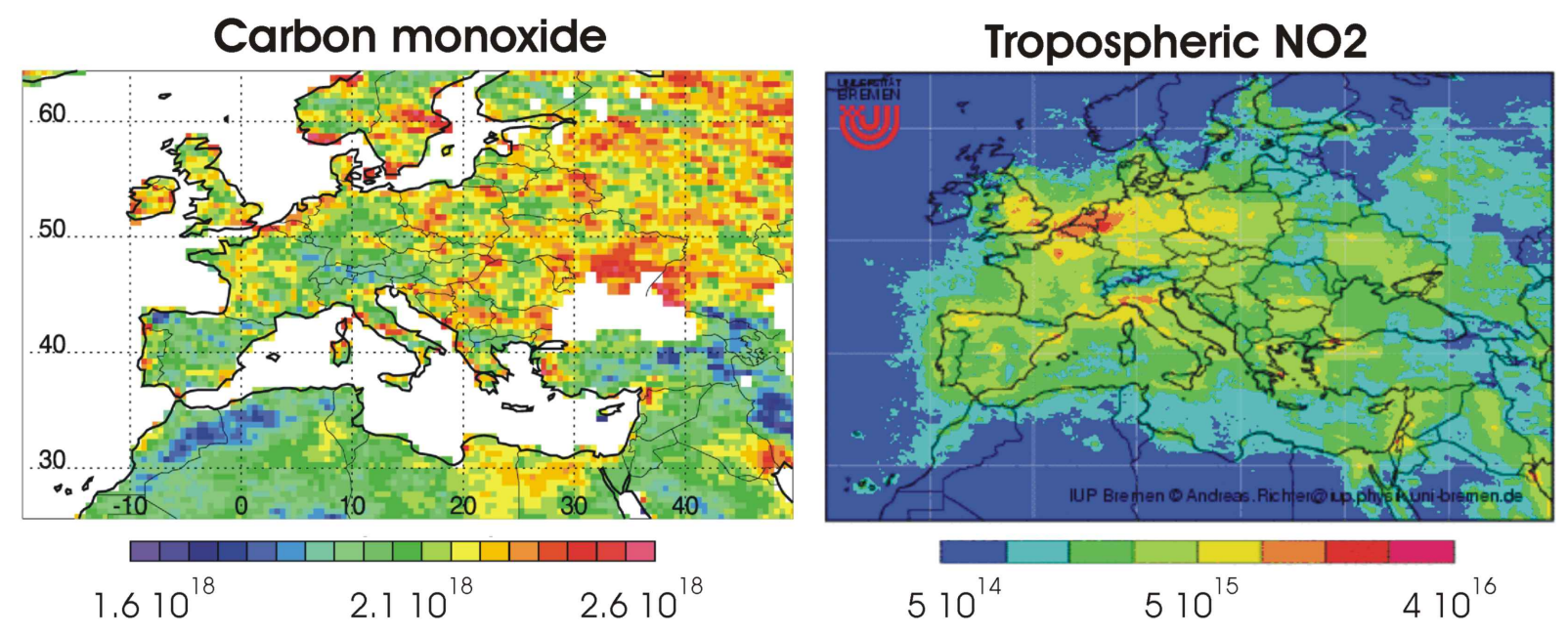

Fig. 12. Comparison of SCIAMACHY CO (left) and $\mathrm{NO}_{2}$ (right) measurements over Europe for 2004 (the $\mathrm{NO}_{2}$ has been retrieved at the University of Bremen by A. Richter (Richter et al., 2005)).

creases rather than the noise of a few detector pixels. Further studies are needed to investigate this in more detail.

In the remaining part of this section we focus on more regional results. Especially for air quality measurements it would be very interesting to analyze to what extent it is possible with SCIAMACHY to see elevated CO corresponding to heavily populated regions including individual cities as is possible with, for example, the SCIAMACHY $\mathrm{NO}_{2}$ measurements. Figure 12 shows year 2004 CO over Europe, northern Africa, and the Middle East compared to tropospheric $\mathrm{NO}_{2}$. The tropospheric $\mathrm{NO}_{2}$ has been retrieved at the University of Bremen also using a DOAS algorithm (Richter et al., 2005). Various polluted regions in Europe are clearly visible in the $\mathrm{NO}_{2}$ (London area, Ruhr area in western Germany, Po valley in northern Italy) as well as individual cities (e.g., Madrid, Barcelona, Paris, Rome). For CO the picture is not so clear although elevated $\mathrm{CO}$ is also visible over a number of regions where also $\mathrm{NO}_{2}$ is high (e.g., London area, Ruhr area, large parts of the Netherlands and Belgium, Po valley, the area around Rome, Lisbon, Casablanca, Izmir, Kuwait, southern Iraq). Of course a one-to-one relationship between the $\mathrm{CO}$ and the $\mathrm{NO}_{2}$ is not to be expected because of differences of the two gases with respect to their sources, atmospheric lifetimes, and transport.

What are the expected signals and the detection limits? The single measurement precisions (random errors due to instrument noise) are, for best cases (e.g., high albedo, high sun, high tropospheric $\mathrm{NO}_{2}$ ), about $10 \%$ for both $\mathrm{CO}$ and tropospheric $\mathrm{NO}_{2}$ (the absolute errors are typically larger). For CO this corresponds roughly to a column change of $2 \times 10^{17}$ molecules $/ \mathrm{cm}^{2}$ (assuming a typical total column of $2 \times 10^{18}$ molecules $/ \mathrm{cm}^{2}$, see Fig. 12). For tropospheric $\mathrm{NO}_{2}$ this corresponds to about $2 \times 10^{15}$ molecules $/ \mathrm{cm}^{2}$ (assuming a tropospheric column of $2 \times 10^{16}$ molecules $/ \mathrm{cm}^{2}$, see Fig. 12). What are the typical source strengths of polluted regions including cities? For both $\mathrm{CO}$ and $\mathrm{NO}_{2}$ the University of Cologne, Germany, produces daily air quality forecasts available on the EURAD web page (http://www.eurad. uni-koeln.de) for various spatial regions. For $\mathrm{NO}_{2}$ near surface concentrations of $100 \mu \mathrm{g} / \mathrm{m}^{3}$ roughly corresponding to $100 \mathrm{ppbv}$ are often reached. For CO the concentration changes are below $1000 \mu \mathrm{g} / \mathrm{m}^{3}$ corresponding to $1000 \mathrm{ppbv}$ (a value that is typical for, for example, the most polluted streets in Bremen, but this is not a typical average concentration for the footprint size of SCIAMACHY). For the following we assume similar source strength for both $\mathrm{NO}_{2}$ and $\mathrm{CO}$ corresponding to an increase of the volume mixing ratio (VMR) in the range 10-100 ppbv. An increase of the VMR of $100 \mathrm{ppbv}$ in the lowest $1 \mathrm{~km}$ of the atmosphere corresponds to a vertical column change of about $2 \times 10^{17}$ molecules $/ \mathrm{cm}^{2}$ which roughly corresponds to the single measurement precision of the SCIAMACHY CO measurements but is significantly larger than the estimated error for $\mathrm{NO}_{2}$. This discussion shows that the detection of enhanced levels of the two pollutants due to cities with SCIAMACHY is considerably more challenging for $\mathrm{CO}$ compared to $\mathrm{NO}_{2}$. Furthermore, there are two additional complications: the footprint size of the $\mathrm{CO}$ measurements is typically twice as large as the footprint size of the $\mathrm{NO}_{2}$ measurements and the lifetime of $\mathrm{CO}$ is much larger (about two month) compared to $\mathrm{NO}_{2}$ (hours to days). These considerations may explain why the $\mathrm{CO}$ shown in Fig. 12 appears to be significantly noisier compared to $\mathrm{NO}_{2}$. The estimated precisions were single measurement precisions not representative for yearly averages. 


\section{Population density CO SCIAMACHY}

\section{SCIAMACHY-MOPITT}

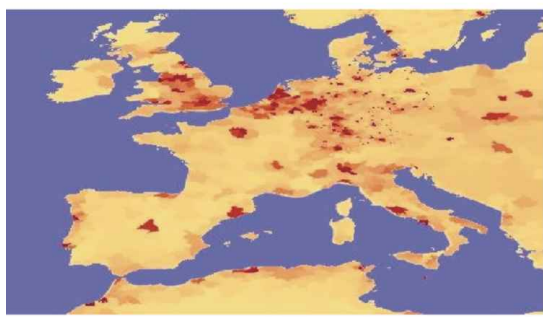

Europe
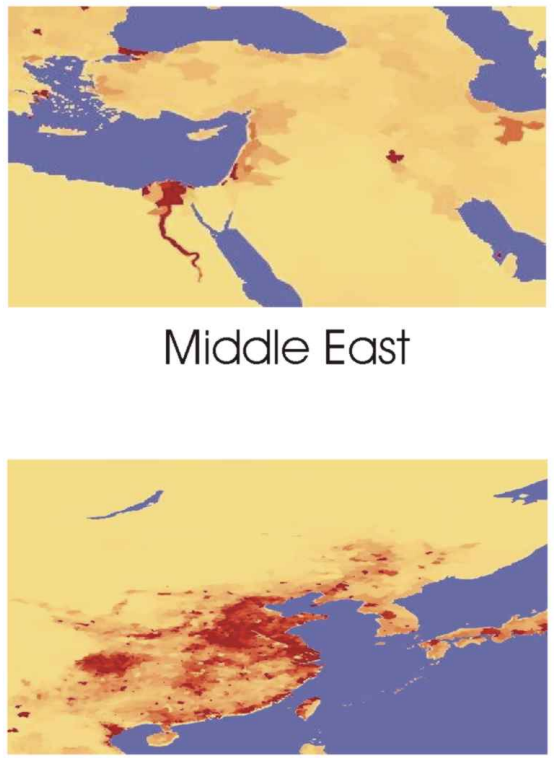

China

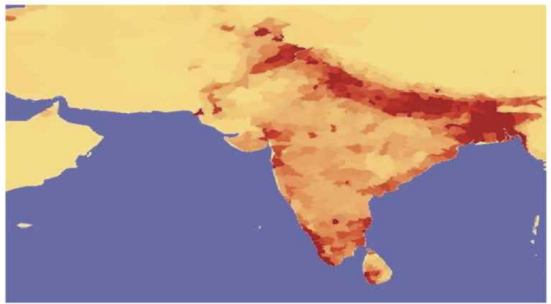

India
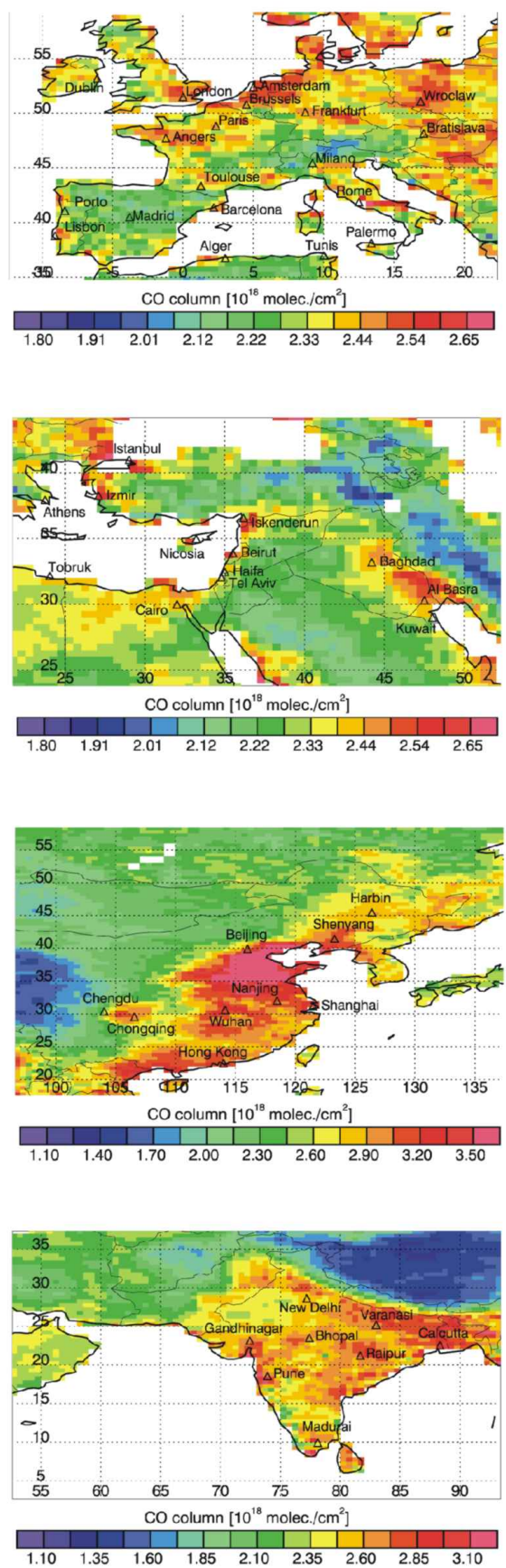
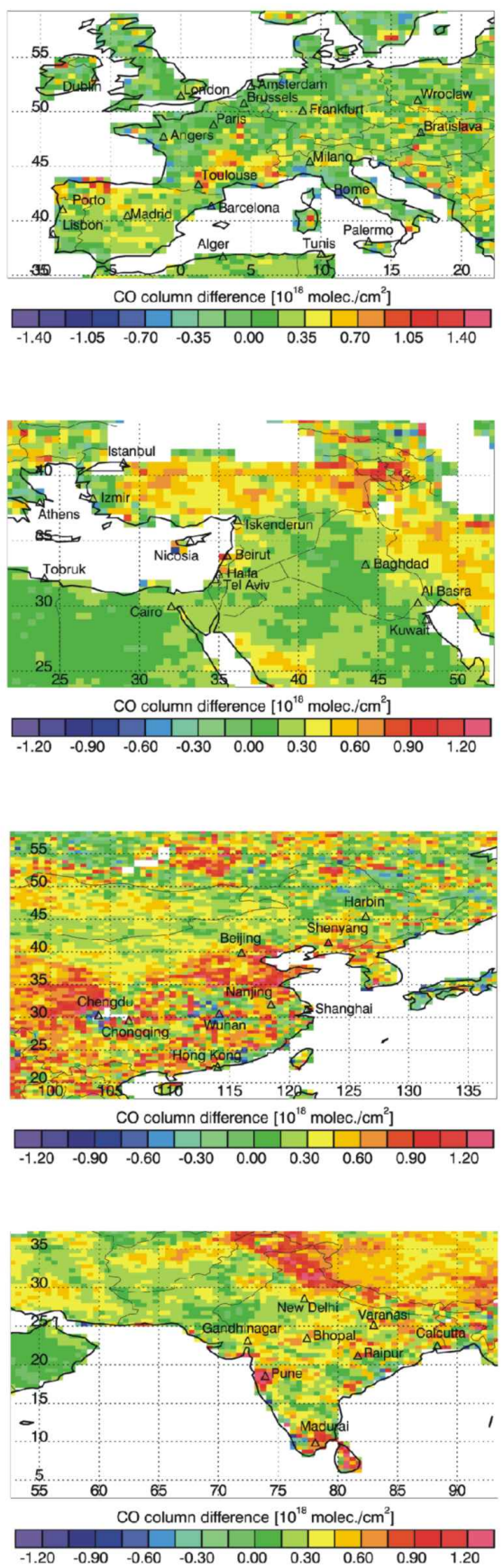

Fig. 13. SCIAMACHY CO vertical columns (middle) over four regions (from top to bottom: Europe, Middle East, China, and India). The left column shows the population density for these regions and the right column shows the CO column difference SCIAMACHY-MOPITT. The population density map has been obtained from http://veimages.gsfc.nasa.gov/116/pop_density.jpg.

SCIAMACHY achieves global coverage in about six days, i.e., each location is revisited about every six days (depending on latitude). This results in about 60 measurements per location each year. Assuming that $30 \%$ of these measure- ments are useful (negligible cloud cover etc.) this results in 18 measurements per year. Assuming that the retrieval precision improves with the square root of the number of measurements added gives an improvement of about a factor of 4 re- 

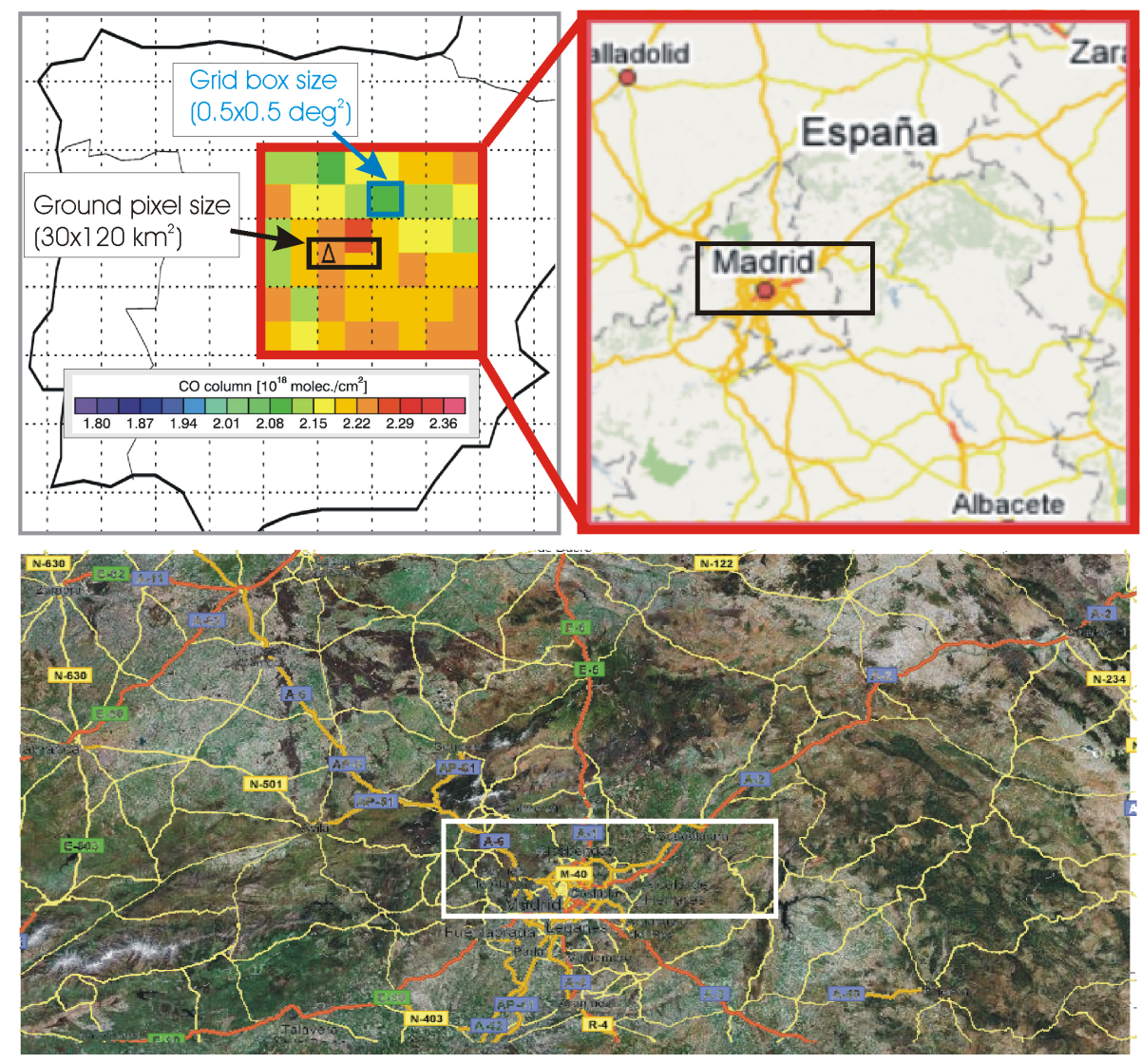

Fig. 14. The top left panel shows a zoom into the map shows in Fig. 13 focussing on the region around Madrid in central Spain. Compared to Fig. 13 the color scale has been optimimized for Madrid and surroundings. Each colored square corresponds to the average CO column within a 0.5 degree latitude by 0.5 degree longitude grid box. The triangle shows the location of Madrid and the black rectangle shows the size of a SCIAMACHY ground pixel. The spatial extent of Madrid and an image of Madrid and its surroundings are shown in the top right and bottom panels, respectively. Both maps have been obtained from http://maps.google.es. The size of a SCIAMACHY ground pixel is shown as a black rectangle in the top left panel and as a white rectangle in the bottom panel.

sulting in a precision of about $5 \times 10^{16}$ molecules $/ \mathrm{cm}^{2}(2.5 \%$ of a typical column of $2 \times 10^{18}$ molecules $/ \mathrm{cm}^{2}$ ) for a yearly average. This shows that due to the relatively small number of measurements for a given location per year the improvement due to averaging helps but only marginally.

Figure 13 shows more regional results obtained from averaging three years of data. The results for Europe indicate that averaging improves the precision as the $\mathrm{CO}$ over Europe appears to be less noisy compared to Fig. 12 (see, e.g., London area, the Netherlands, Belgium, and western Germany). Elevated $\mathrm{CO}$ over highly populated areas is also visible for a number of regions and cities outside Europe, e.g., along the Mediterranean Sea (such as Izmir, Iskenderun, Beirut, Haifa), the region between Bagdad and Basra, as well as the populated areas of India and China (see the population density maps added on the left hand side of Fig. 13). To investigate if the SCIAMACHY CO columns are higher compared to MOPITT, especially over the populated CO source regions, the column difference with respect to MOPITT is shown on the right hand side. Because of the different altitude sensitivities of SCIAMACHY, which is sensitive to the boundary layer, and MOPITT, which has low boundary layer sensitivity, one would expect that the SCIAMACHY columns are higher especially over $\mathrm{CO}$ source regions. Figure 13 is an attempt to investigate this. For Europe however the picture is not very clear except for the Po valley, where the SCIAMACHY CO values are higher. For the Middle East SCIAMACHY measures higher CO over Beirut and Haifa and over other regions which are however not confined to well defined source areas. For China and India SCIAMACHY measures higher $\mathrm{CO}$ in the region south of Beijing and along the Ganges (however more northward compared to the maxima of the population density map). Similar results are shown in Buchwitz et al. (2006) for WFMDv0.5 year 2003 CO. For India the most localized enhanced values measured by SCIAMACHY compared to MOPITT can be observed over Pune. 
For Europe Fig. 13 suggests that SCIAMACHY does not observe enhanced levels of $\mathrm{CO}$ over several major cities such as Madrid or Paris. A zoom into Fig. 13 however reveals that $\mathrm{CO}$ over Paris is enhanced compared to its surroundings. For Madrid this is not so easy to see because the color scale is not appropriate for Madrid and surroundings. Figure 14 shows a zoom into the region around Madrid using a more appropriate color scale showing that $\mathrm{CO}$ near Madrid is in fact enhanced. Figure 14 however also illustrates some problems related to the detection of elevated $\mathrm{CO}$ for individual cities such as the large footprint size and problems due to inhomogeneous scenes with, for example, large changes of the topography. These effects might explain why the largest $\mathrm{CO}$ values are not measured exactly in the grid box in which Madrid is located but in an adjacent grid box.

\section{Conclusions}

We have presented a three year data set (2003-2005) of global CO columns retrieved from the spectral near-infrared nadir observations of SCIAMACHY. We have shown that despite a number of instrument related issues reasonable to good CO columns can be retrieved. Comprehensive comparison with the CO column data product of MOPITT has shown that agreement is typically within about $20 \%$ with the best agreement found for 2004. We have shown that elevated levels of $\mathrm{CO}$ correlate with population density and that elevated $\mathrm{CO}$ can even be detected for individual cities.

Future work will aim at getting a better understanding of the data quality including studies to investigate the differences with respect to MOPITT (especially for the years 2003 and 2005) taking into account the different altitude sensitivities of both sensors but also time dependent changes of the SCIAMACHY instrument. This will include a detailed comparison also with other reference data such as local ground based FTIR measurements and global model simulations. We will also aim at improving the $\mathrm{CO}$ retrieval precision by using a larger spectral fitting window covering more $\mathrm{CO}$ lines.

The SCIAMACHY WFM-DOAS version 0.6 year 20032005 data set is available from the authors on request. Figures of monthly and yearly means for the entire 20032005 time period are available on the WFM-DOAS web site http://www.iup.uni-bremen.de/sciamachy/NIR_NADIR_ WFM_DOAS.

Acknowledgements. We thank ESA and DLR for providing us with the SCIAMACHY Level 1 data and the SCIAMACHY calibration team (DLR, SRON, ESA, University of Bremen, and others) for continuously improving the quality of the spectra. We thank the MOPITT teams at NCAR and University of Toronto for the MOPITT Level 2 Version 3 data which have been obtained via the NASA Langley DAAC. The AATSR fire count data have been obtained from ESA/ESRIN. Funding for this study came from the German Ministry for Research and Education
(BMBF) via DLR-Bonn (50EE0027, project SADOS), from ESA (GMES/PROMOTE) and from the University and the State of Bremen. We acknowledge exchange of information within the European Commission Network of Excellence ACCENT.

Edited by: R. Volkamer

\section{References}

Bergamaschi, P., Hein, R., Heimann, M., and Crutzen, P. J.: Inverse modeling of the global $\mathrm{CO}$ cycle, 1 . Inversion of $\mathrm{CO}$ mixing ratios, J. Geophys. Res., 105, 1909-1927, 2000.

Bovensmann, H., Burrows, J. P., Buchwitz, M., Frerick, J., Noël, S., Rozanov, V. V., Chance, K. V., and Goede, A.: SCIAMACHY Mission Objectives and Measurement Modes, J. Atmos. Sci., 56, 127-150, 1999.

Bremer, H., Kar, J., Drummond, J. R., Nichitu, F., Zou, J., Liu, J., J. C. Gille, J. C., Deeter, M. N., Francis, G., Ziskin, D., and J. Warner, The Spatial and Temporal Variation of MOPITT CO in Africa and South America: A Comparison With SHADOZ Ozone and MODIS Aerosol, J. Geophys. Res., 109(D12), D12304, doi:10.1029/2003JD004234, 2004.

Buchwitz, M., Rozanov, V. V., and Burrows, J. P.: A correlated-k distribution scheme for overlapping gases suitable for retrieval of atmospheric constituents in the visible/near-infrared spectral region, J. Geophys. Res., 105, 15 247-15 261, 2000.

Buchwitz, M., Rozanov, V. V., and Burrows, J. P.: A near infrared optimized DOAS method for the fast global retrieval of atmospheric $\mathrm{CH}_{4}, \mathrm{CO}, \mathrm{CO}_{2}, \mathrm{H}_{2} \mathrm{O}$, and $\mathrm{N}_{2} \mathrm{O}$ total column amounts from SCIAMACHY/ENVISAT-1 nadir radiances, J. Geophys. Res., 105, 15 231-15 246, 2000.

Buchwitz, M., de Beek, R., Bramstedt, K., Noël, S., Bovensmann, H., and Burrows, J. P.: Global carbon monoxide as retrieved from SCIAMACHY by WFM-DOAS, Atmos. Chem. Phys., 4, 19451960, 2004, http://www.atmos-chem-phys.net/4/1945/2004/.

Buchwitz, M., de Beek, R., Noël, S., Burrows, J. P., Bovensmann, H., Bremer, H., Bergamaschi, P., Körner, S., and Heimann, M.: Carbon monoxide, methane, and carbon dioxide retrieved from SCIAMACHY by WFM-DOAS: year 2003 initial data set, Atmos. Chem. Phys., 5, 3313-3329, 2005, http://www.atmos-chem-phys.net/5/3313/2005/.

Buchwitz, M., de Beek, R., Noël, S., Burrows, J. P., Bovensmann, H., Schneising, O., Khlystova, I., Bruns, M., Bremer, H., Bergamaschi, P., Körner, S., and Heimann, M.: Atmospheric carbon gases retrieved from SCIAMACHY by WFM-DOAS: version $0.5 \mathrm{CO}$ and $\mathrm{CH}_{4}$ and impact of calibration improvements on $\mathrm{CO}_{2}$ retrieval, Atmos. Chem. Phys., 6, 2727-2751, 2006, http://www.atmos-chem-phys.net/6/2727/2006/.

Deeter, M. N., Emmons, L. K., Francis, G. L., Edwards, D. P., Gille, J. C., Warner, J. X., Khattatov, B., Ziskin, D., Lamarque, J.-F., Ho, S.-P., Yuding, V., Attie, J.-L., Packman, D., Chen, J., Mao, D., and Drummond, J. R.: Operational carbon monoxide retrieval algorithm and selected results for the MOPITT instrument, J. Geophys. Res., 108, 4399-4409, 2003.

Dils, B., De Mazière, M., Müller, J. F., Blumenstock, T., Buchwitz, M., de Beek, R., Demoulin, P., Duchatelet, P., Fast, H., Frankenberg, C., Gloudemans, A., Griffith, D., Jones, N., Kerzenmacher, T., Mahieu, E., Mellqvist, J., Mikuteit, S., Mittermeier, R. L., 
Notholt, J., Schrijver, H., Smale, D., Strandberg, A., Stremme, W., Strong, K., Sussmann, R., Taylor, J., van den Broek, M., Warneke, T., Wiacek, A., and Wood, S.: Comparison between SCIAMACHY and ground-based FTIR data for total columns of $\mathrm{CO}, \mathrm{CH}_{4}, \mathrm{CO}_{2}$ and $\mathrm{N}_{2} \mathrm{O}$, Atmos. Chem. Phys., 6, 1953-1976, 2006,

http://www.atmos-chem-phys.net/6/1953/2006/.

Dils, B., De Mazière, M., Blumenstock, T., Hase, F., Kramer, I., Mahieu, E., Demoulin, P., Duchatelet, P., Mellqvist, J., Strandberg, A., Buchwitz, M., Khlystova, I., Schneising, O., Velazco, V., Notholt, J., Sussmann, R., and Stremme, W.: Validation of WFM-DOAS v0.6 $\mathrm{CO}$ and v1.0 $\mathrm{CH}_{4}$ scientific products using European ground-based FTIR measurements, proceedings of the Third Workshop on the Atmospheric Chemistry Validation of ENVISAT (ACVE-3), 4-7 Dec. 2006, ESA/ESRIN, Frascati, Italy, ESA Publications Division Special Publication SP642 (CD), 2006.

Frankenberg, C., Platt, U., and Wagner, T.: Retrieval of CO from SCIAMACHY onboard ENVISAT: Detection of strongly polluted areas and seasonal patterns in global $\mathrm{CO}$ abundances, Atmos. Chem. Phys., 5, 1639-1644, 2005, http://www.atmos-chem-phys.net/5/1639/2005/.

Gloudemans, A. M. S., Schrijver, H., Kleipool, Q., van den Broek, M. M. P., Straume, A. G., Lichtenberg, G., van Hess, R. M., Aben, I., and Meirink, J. F.: The impact of SCIAMACHY nearinfrared instrument calibration on $\mathrm{CH}_{4}$ and $\mathrm{CO}$ total columns, Atmos. Chem. Phys., 5, 2369-2383, 2005,

http://www.atmos-chem-phys.net/5/2369/2005/.
Gloudemans, A. M. S., Krol, M. C., Meirink, J. F., de Laat, A. J. T., van der Werf, R., Schrijver, H., van den Broek, M. M. P., and Aben, I.: Evidence for long-range transport of carbon monoxide in the southern hemisphere from SCIAMACHY observations, Geophys. Res. Lett., 33, L16807, doi:10.1029/2006GL026804, 2006.

de Laat, A. T. J., Gloudemans, A. M. S., Schrijver, H., van den Broek, M. M. P., Meirink, J. F., Aben, I. and Krol M., Quantitative analysis of SCIAMACHY carbon monoxide total column measurements, Geophys. Res. Lett., 33, L07807, doi:10.1029/2005GL025530, 2006.

Richter, A., Burrows, J. P., Nüß, H., Granier, C., and Niemeier, U., Increase in tropospheric nitrogen dioxide over China observed from space, Nature, 437, 129-132, doi:10.1038/nature04092, 2005.

Rothman, L. S., Barbe, A., Benner, et al.: The HITRAN molecular spectroscopic database: edition of 2000 including updates through 2001, J. Quant. Spectrosc. Radiat. Transfer, 82, 5-44, 2003.

Rothman, L. S., Jaquemart, D., Barbe, A., et al.: The HITRAN 2004 molecular spectroscopic database, J. Quant. Spectrosc. Radiat. Transfer, 96, 139-204, 2005. 